\title{
THE TRANSFER OF HEAT THROUGH SUN HELMETS
}

\author{
BY
}

\author{
P. S. H. HENRY AND W. H. REES
}

From the British Cotton Industry Research Association, Manchester.

\section{Introduction and Summary}

During the early years of the war of 1939-45, work was carried out in the laboratories of the British Cotton Industry Research Association on the heat protection afforded by military sun helmets which, at that time, were considered to be an essential article of tropical kit. Later on in the war, the use of sun helmets was discontinued, but it has been decided to publish the results of the laboratory experiments as they may be of interest in connexion with civilian helmets and also as illustrating the general method of attack on the problem of the transfer of heat through a complex system such as a sun helmet.

The basic problem was to produce a helmet which, when exposed to tropical sunshine, allowed as little as possible of the heat it received to be transmitted to the head, whilst permitting free circulation of air round the head so that moisture might evaporate and a certain amount of direct cooling of the head take place. The helmet had to be easily manufactured with little disturbance of established methods, and had to employ the minimum of scarce materials.

To achieve the minimum transmission of heat, it is important to obtain a rough idea of the relative importance of the various processes of heat transfer taking place. The most effective attack on the problem requires a knowledge of what is happening inside and outside the helmet. For instance, if we know that in an aluminium-lined helmet radiation is responsible for only a small percentage of the total heat transfer, we need not waste time in trying to reduce it further until we have examined the other modes of heat exchange. This paper describes the experimental work by which the relative importance of the various heat exchanges is determined. The flow of heat through a sun helmet is analysed into its component parts, and the way in which these combine together is worked out with the aid of an electrical analogy. Experiments are described in which the separate heat exchanges are determined, the effects on them of changes in the helmet structure are examined, and in particular, the importance of the metallic lining is brought out. The results are used to discuss the possibility of improving the helmets, and the conclusions are reached that considerable improvements could be effected by the use of a thicker, lighter material for the body of the helmet, and by increasing the size of the apertures of the top ventilator.

\section{The Modes of Heat Transfer}

The chief exchanges of heat are shown in fig. 1, where the letters $\mathbf{R}^{1}, \mathbf{R}, \mathrm{C}$, and $\mathrm{V}$ stand for high temperature radiation, low temperature radiation, conduction, and convection respectively. The figure

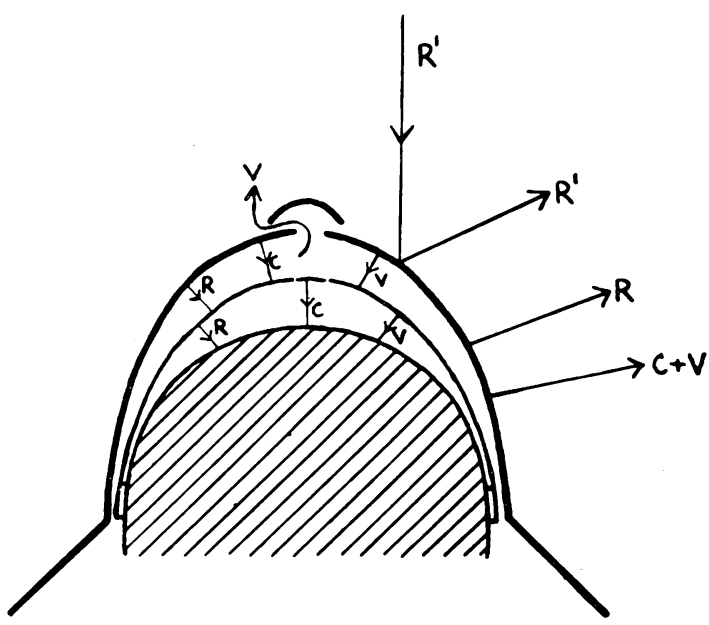

FIG. 1.-Cross-section of army sun helmet in position.

shows a helmet with dome. (The Army pattern sun helmet in existence at the time of this investigation consisted of a wool felt body stiffened with shellac, covered on the outside with khaki drill, and lined with aluminium foil or aluminized fabric. The helmet was supported away from the head by small spacers which connected it to the head band whilst allowing a gap between the latter and the helmet. Sometimes a 'drop lining' (sometimes referred to as a dome) of aluminium foil or aluminized fabric was attached to the head band as shown in the diagram.) The exchanges without a dome would be similar except that the head would take the place of the dome. No direct convection of heat from the head to the outer air is shown because the domes hitherto supplied had been practically unventilated (they had four small holes in the top, but it is doubtful whether these had much effect). No penetration of radiation through the helmet is shown, since experiments with 
a sensitive thermopile failed to detect any. In the absence of a dome, or with a well-ventilated dome, there would probably be cooling of the head by evaporation of moisture followed by convection away of the vapour. Without ventilation the accumulation of vapour would soon restrict evaporation. (We are referring, of course, only to that part of the head inside the hat band.) The cooling essential to health is provided by evaporation, directly from the head through the helmet and indirectly from the body to which the overheated blood of the scalp is carried by the veins.

Let us. now consider the different heat exchanges in turn.

\section{(a) High-temperature Radiation}

This is the form in which most of the heat arrives at the helmet, either as direct sunlight or as sunlight reflected from surrounding objects. Sunlight has its maximum energy (reckoned on a wave-length basis) near to a wave-length of $0.5 \mu$; most of its energy is in the visible spectrum, with roughly 5 per cent. in the ultra-violet and 20 per cent. in the infrared, mostly fairly 'near,' i.e. with wave-lengths not greater than, say, $2 \mu$. Only the radiation which is absorbed by the helmet goes to heat it up, and if we could cover the helmet with a perfectly reflecting material we should have no need to bother about the internal insulation. Since, however, most of the radiation concerned is in the visible range, such a helmet would appear white or metallically reflecting, and this, though permissible for civilian purposes, is ruled out on account of visibility for military use. The best that can be done is to find a fabric which is as light in colour as military considerations allow; and which reflects well in the infra-red. The latter property is desirable for a fabric which is to serve as camouflage against green vegetation, since chlorophyll reflects the near infra-red strongly. Thus there are more reasons than one for producing such a fabric. For civilian use there is no doubt that white is the best colour. A bright metallic surface would be better still, but might not be acceptable on aesthetic grounds.

\section{(b) Low-temperature Radiation}

This is the radiation exchanged between the various parts of the helmet and the head, and between the outside of the helmet and the surroundings. The energy maximum in its spectrum is in the neighbourhood of $9 \mu$ at body temperatures. There is evidence that most, if not all, textile materials are practically 'black' to these wavelengths, i.e. they absorb and radiate to the maximum extent (Rees and Ogden, 1944 and 1946). On the other hand, many bright metal surfaces, if clean, radiate and absorb very little here, though a very thin film of organic material (e.g. grease or varnish) or of oxide is sufficient to raise the emissivity a great deal. At wave-lengths such as these the reflecting power and emissivity of a clean metal surface are determined almost solely by the electrical con- ductivity of the metal, the reflection being more nearly complete the higher the conductivity (Rubens and Hagen, 1903). Radiation and absorption characteristics of particular metals are not noticeable at wave-lengths longer than about $5 \mu$. Thus silver, copper, and gold would reflect more than the aluminium which is used for lining helmets but the first two tarnish reádily, whilst the third is rather expensive, even as thin foil. Tin would form a reasonable substitute for aluminium, for its emissivity in the polished state is practically the same as that of aluminium. Small differences in emissivity would have little effect on the performance of a helmet, especially when one considers that the surface is likely to get soiled in use.

The total energy radiated by a given surface is proportional to the fourth power of its absolute temperature, and the energy received by direct radiation from the surroundings (supposed to be at a uniform temperature) is proportional to the fourth power of the temperature of the solid surroundings. Thus the net rate of loss of heat by the surface considered can be written $a T_{1}{ }^{4}-a T_{2}{ }^{4}$ where $T_{1}$ and $T_{2}$ are the absolute temperatures of surface and surroundings respectively. (That the coefficients of the two terms must be equal is evident from the fact that if $T_{1}=T_{2}$ there must be no net loss of heat.) Now

$$
a\left(T_{1}^{4}-T_{2}^{4}\right)=a\left(T_{1}^{2}+T^{2}\right)\left(T_{1}+T_{2}\right)\left(T_{1}-T_{2}\right)
$$

so that, if $T_{1}$ and $T_{2}$ do not vary widely, the rate of heat transfer is approximately proportional to the temperature difference.

If we can neglect radiation reflected back and forth more than once between the surface and its surroundings, the coefficient $a$, and hence the rate of heat transfer, will be proportional to the product of the emissivities of the surface and its surroundings. This will be so if either the surface or surroundings are nearly ' black bodies,' and in this case the heat transfer will be proportional to the emissivity of the other surface. If both are metallic and differ appreciably from black bodies, we must take account of inter-reflections, and the heat transfer will be greater than would follow from the above approximation. We shall see that in practice it is unnecessary to have two metallic surfaces facing each other unless they are liable to get very badly contaminated. We need not, therefore, consider this case further here.

The radiated heat transfer between two surfaces inside a helmet will depend upon the extent to which one surrounds the other, but not on the distance between them, thus differing from conducted heat transfer.

\section{(c) Convection of Heat}

This includes all heat carried from one place to another by motion of the air, whether the latter is due to external causes (winds, motion of the wearer, etc.) or to circulation produced by the uneven temperature distribution. Following the usual terminology these two cases will be referred to as ' forced' and 'natural' convection respectively. 
Probably a large part of the heat loss from the outer surface of the helmet is due to convection. Inside the helmet the motion of the air is more restricted and the heat transfer correspondingly smaller. The narrower the space the more restricted is the air motion, and within limits the less we should expect the convected heat transfer to be, particularly if the gap is narrow enough to prevent turbulence. Some experimental confirmation of this will be found later.

Convection has been studied quantitatively for simple shapes of surface, principally horizontal cylinders (Roberts, 1933). The results are not, of course, applicable to helmets, but we may expect that the rate of heat transfer will still be nearly proportional to the temperature difference (where this is not large) as it is in the case of the cylinders.

\section{(d) Conduction}

We shall be concerned with conduction through the material of the helmet and across the air spaces inside. With thick material like that used for pith helmets the difference in temperature between the outer and inner surfaces may be considerable, and the insulation due to the material an appreciable portion of the whole.

The transfer of heat by convection discussed in the last section involves heat exchanges between the air and solid surfaces, and, therefore, conduction of heat through the air. Thus it is not strictly permissible to consider the conduction and convection separately. None the less, it is convenient to assume as constituting the conduction a transfer of heat equal in all cases to that which would take place if the air were stationary and to ascribe any observed excess over this to convection. This arbitrary splitting up of the heat transfer is legitimate so long as we use it with discretion to obtain a qualitative picture of the process. A similar idea is used in text books on heat conduction to superpose different conduction processes, each of which could occur by itself, to give the solution to a given problem. It is there shown to be exactly legitimate for stationary media, though not, in its simple form, for moving media.

The amount of heat transferred by conduction is proportional to the temperature difference, and inversely to the thickness of the medium.

\section{(e) Convection and Diffusion of Moisture}

Considerable cooling of the bare head in hot weather may take place by evaporation of perspiration, and it is desirable that the helmet should allow this to continue. Diffusion of water vapour through air is a slow process, and, for appreciable evaporation from the head, ventilation is essential. Owing to the similarity - from the mathematical point of viewof the processes involved, it is probable that evaporation of moisture and direct cooling of the head by thermal convection will run parallel, and as the ventilation varies, the amounts of each are likely to be proportional so long as the supply of moisture at the head and other conditions remain constant.

\section{The Electrical Analogy}

We have now discussed the various means of heat transfer which may contribute to the total effect. Before considering how they may be determined experimentally we must consider how they combine to give the properties of the helmet as a whole. Here electrical terminology is useful. We can speak of the radiation, conduction, and convection from helmet to dome as being in parallel with each other; and of the passage from helmet to dome as being in series with that from dome to head. If we assume that the various rates of heat transfer are proportional to the temperature differences producing them, the analogy can be taken further than mere terminology. If heat flow and temperature correspond to current and potential respectively, heat flow divided by the temperature difference producing it corresponds to a conductance, and the reciprocal of this quantity to a resistance. Then we can use the usual laws of combination, adding the resistances of elements in series, and the conductances of those in parallel. We can thus draw fig. 2, which shows the 'equivalent circuit' for a helmet with dome. The letters have the same significance as in fig. 1 and are now to be taken as representing conductances. A constant current corresponding to the absorbed radiation from the sun is supposed to enter at the top of the diagram.

Batteries are shown connecting the head, the air, and the solid surroundings with ' earth' to allow for the fact that the head, air, and surroundings are at different temperatures, which are maintained. for the head, by the thermal regulation of the body, and for the air and surroundings by their large heat capacity. The 'earth' in the thermal case may be thought of as the ground at a depth where its temperature will not vary with the external conditions. When we are concerned with an artificial ' head ' such as that used in our experiments, we must substitute for the head battery a conducting path representing loss of heat from the 'head.' The effects of external ventilation are shown dotted.

If the letters $C_{1}, R_{2}$, etc., denote the conductances of the various steps, the over-all conductance $C$ of the helmet is given by

$\frac{1}{C}=\frac{1}{C_{1}}+\frac{1}{R_{2}+C_{2}+V_{2}}+\frac{1}{R_{3}+C_{3}+V_{3}}$.

If the rate of supply of energy from the sun is $H$ units, and of this a fraction $a$ is absorbed by the helmet, we have

$$
\begin{aligned}
a H=C & \left(T_{\mathrm{O}}-T_{\mathrm{H}}\right)+\left(C_{4}\right. \\
& \left.+V_{4}\right)\left(T_{\mathrm{O}}-T_{\mathrm{A}}\right) \\
& +R_{4}\left(T_{\mathrm{O}}-T_{\mathrm{S}}\right) \ldots \\
=K\left(T_{\mathrm{O}}-\theta\right) &
\end{aligned}
$$

where $K=C+C_{4}+V_{4}+R_{4}$

and $\theta=\frac{C T_{\mathrm{H}}+\left(C_{4}+V_{4}\right) T_{\mathrm{A}}+R_{4} T_{\mathrm{S}}}{C+C_{4}+V_{4}+R_{4}}$.

the symbols being those used on fig. 2. $K$ may be thought of as a 'total conductance' and $\theta$ as a weighted mean of the temperatures surrounding the helmet. 
Thus the temperature of the outer surface of the helmet is

$$
T_{\mathrm{o}}=\theta+\frac{a H}{K} \quad \cdot \quad \cdot .
$$

and the rate of arrival of heat at the head is

$$
Q=C\left(T_{\mathrm{o}}-T\right)=C . \frac{a H}{K}+C\left(\theta-T_{\mathrm{H}}\right) .
$$

The first term of this expression is the one which is of interest in connexion with protection from the sun's radiation, and it can be written

$$
Q_{1}=\frac{C}{C+C_{\mathrm{E}}} a H \quad . \quad . \quad .
$$

where $C_{\mathrm{E}}=C_{4}+V_{4}+R_{4}$, i.e. the 'External Conductance.'

To make this quantity smaller we may decrease $a$ or $C$, or increase $C_{\mathrm{E}}$, as is otherwise obvious. If, however, it should happen that $C$ is comparable with

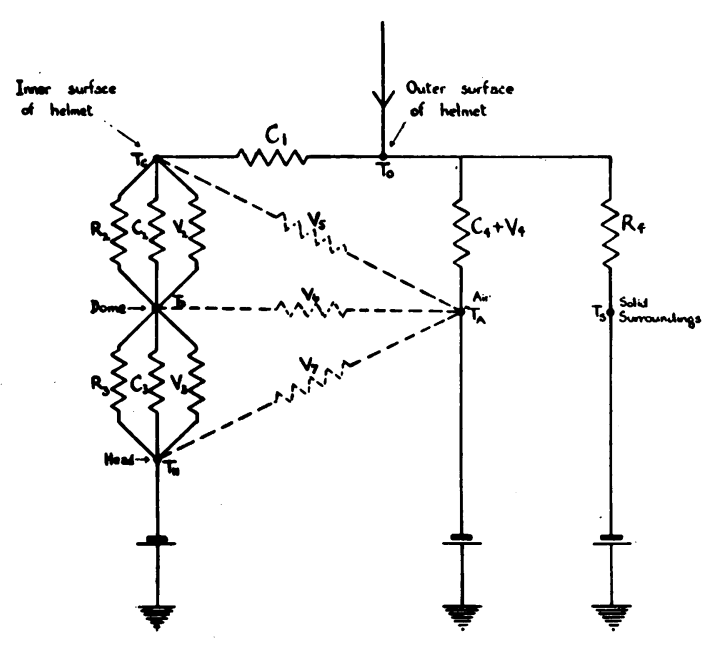

FIG. 2.-Electrical circuit for analogy of heat transfer.

or larger than $C_{\mathrm{E}}$, a given percentage change in $C$ or $C_{\mathrm{E}}$ would not produce a proportionate change in $Q_{1}$. The physical meaning of this is that if the heat lost from the helmet inwards is comparable with that lost outwards, increasing the internal insulation would cause the helmet temperature to rise appreciably and this would partially offset the good effect of the increase in insulation. Experimental evidence will be presented later, however, that, even with the least insulated helmet, $C_{E}$ is not less than five times $C$. Hence, in practice, we can assume that the full benefit would be received from a decrease in $C$ or an increase in $\mathrm{C}_{\mathrm{E}}$.

Examples of the numerical application of the methods described in this section will be found in later sections, particularly in the appendix, where head temperature rises are calculated for helmets lined with various materials whose emissivities had been determined with a Leslie cube and thermopile.

\section{Determination of Internal Heat Exchanges}

Apart from the determination of the fraction of the sunlight absorbed, which depends only upon the material with which the helmet is covered, the experiments had to be carried out with the apparatus. immediately available, which was that originally set up for the empirical testing of helmets. In this the helmet rested upon a plaster of Paris ' head ' and was subjected to radiation from an electric radiator placed vertically above it. The rise in temperature of the surface of the head after two hours was taken as a measure of the flow of heat to the head, and the temperatures of the various parts of the helmet could be measured by thermocouples. The separation of the various modes of heat transfer had to be effected by repeating such experiments under different conditions in which the modes operated in various proportions. The method is admittedly not entirely accurate since the head has not reached equilibrium in 2 hours, and its temperature rise in this time is not an exact measure either of the rate of passage of heat to it at that instant, or of the total amount of heat it has received in 2 hours. It would have been preferable to have kept the temperature of the head constant while measuring the heat influx. This, however, would have had to be somewhat elaborate, and since quick results were needed, use was made of the existing apparatus which had already been set up for the empirical comparison of different commercial helmets. It is considered that, in comparing helmets insulated in various ways, the temperature rise should give a rough relative measure of the rate of heat transfer. Consequently the results quoted in this report should be regarded as indicating orders of magnitude only.

With the unventilated helmet (i.e. the helmet with its 'chimney' and the space between helmet and head band stopped up) without a dome there are three internal conductances to be determined: those due to radiation, conduction, and 'natural' convection. Thus a minimum of three experiments. under different conditions is necessary. These were chosen as follows:

(a) Helmet fabric-lined; conductance $=$

$$
R_{2}+C_{2}+V_{2} \text {. . }
$$

(b) Helmet aluminium-lined; conductance $=$

$$
\epsilon R_{2}+C_{2}+V_{2} \text {. . }
$$

(c) Space inside helmet filled with loose cotton lap; conductance $=C_{2}$

It is assumed that the fabric lining to the helmet and the surface of the 'head' have maximum emissivity. The emissivity $\epsilon$ of the aluminium foil was determined in a separate experiment with a Leslie cube and thermopile. Since $\epsilon$ was found to be only 4 per cent., experiment $(b)$ is virtually one in which only conduction and convection take part. In the third experiment it is assumed that all radiation and motion of the air are stopped and that the conduction of heat is equal to that which would take place through still air. This is in approximate accord with experiments on the thermal conductivity of 
cotton laps. The total conductances (in arbitrary units) being thus observed, $R_{2}, C_{2}$ and $V_{2}$ can be calculated by solving the resulting simultaneous equations. For helmets with domes, this process can be applied separately to the space between crown and dome, and between dome and head. When the conductances for the unventilated helmet have been found thus, the extra effect of ventilation can be determined by repeating one or more of the experiments with the ventilating apertures open.

A series of experiments on these lines was carried out on a standard-pattern Army sun helmet made of felt, covered on the outside with a khaki drill and lined inside with 'Rexine.' When an aluminium lining was used it was stuck to the Rexine with rubber solution. Since very little of the lining materials were available and the emissivity could not be determined with the lining in situ, only two experiments were done in which the emissivity of the aluminium lining could be considered as known. In one of these the emissivity of the foil was found immediately before the latter was stuck into the helmet, and in the other the foil was stripped and its emissivity measured immediately after the helmet experiment. There is evidence that the emissivity of a lining may change after the helmet has been standing in the laboratory; hence in all other cases the emissivity of the lining was considered as an unknown to be determined by the helmet experiments. The 'drop lining' referred to here as the 'dome,' was, when used, fastened to the head band which was separated from the helmet by spacers leaving a gap of about $\frac{3}{8}$ in. between band and helmet. The distance between the head and dome was about 1 in. and the only ventilation for this space was given by four holes roughly $-\frac{3}{16}$ in. in diameter at the top of the dome. It is doubtful if these would have much effect The helmet had a small ventilator at the top as well as the gap round the head band.

A 2-kilowatt radiator was used as a source of radiant heat, arranged in a horizontal position above the helmet so that the heat was radiated vertically downwards on to it. A thermopile was used to determine the radiation intensity at the helmet, and the required intensity to simulate tropical sunshine (about $1 \mathrm{cal} . / \mathrm{cm}^{2} \mathrm{~min}$.) was found to be given when the distance from the top of the helmet to the radiator was $60 \mathrm{~cm}$. The helmet was mounted on a plaster of Paris ' head,' to the top surface of which was stuck by means of 'Tenacitine' one junction of a thermocouple made of 34 s.w.g. wires of copper and Constantan. Similar couples were attached in the same way to the dome and helmet surfaces. The helmet was then exposed to the radiation, and the rise in temperature at the crown of the dummy head was measured at intervals for a period of 2 hours. During the test the helmet and head were shielded from extraneous draughts by a black fabric screen reaching down to the floor.

The black body temperature of the radiator was approximately $1180^{\circ} \mathrm{K}$, so that its radiation did not in the least resemble sunlight. This did not matter so long as the outer cover of the helmet remained the same for all the experiments. Comparisons involving different coverings require to be done with radiation as near to sunlight in composition as possible, as described in section 7 .

The results are shown in Table $I$. The temperatures quoted (except the air temperature) are the increases in temperature of the various points after 2 hours' exposure of the helmet to radiation. The helmet used was No. 101, except where otherwise stated.

Helmets A.1 and A.4 were identical with No. 101 in shape, material, and covering, but had different linings. The lining referred to as ' $\mathrm{A} 1$ ' was aluminium foil $7 / 1000$ in. in thickness. That referred to as 'A1. Fab.' was an aluminized fabric.

Three types of domes were used in the experiments, viz.

(1) Outer surface (i.e. facing crown of helmet) fabric, inner surface (i.e. facing head) aluminium foil.

(2) Outer surface aluminium foil, inner surface fabric.

(3) Outer and inner surfaces aluminium foil.

The three types are denoted by the symbols 'Tex-Al,' ' Al-Tex,' and 'Al-Al' respectively, in the column headed 'Dome' in Table 1.

Conductance, as stated earlier, is given by the ratio of heat flow to the temperature difference producing it. Thus, in the present case, the conductance of the helmet-head space is given by the ratio :

Temperature rise of head

(Temperature rise of helmet)-(Temperature rise of head)

Considering first the unventilated helmets without dome, we get values for the conductance of the helmet-head space as follows :-

For the Rexine-lined helmet, experiments 5, 25 and 30 give conductances:

$\frac{24.9}{30.0}=0.83, \frac{24.5}{24.8}=0.99, \frac{27 \cdot 3}{28.3}=0.96 ;$ mean $=0.93$

For the aluminium foil lined helmet, experiments 14 and 42 give:

$\frac{14 \cdot 0}{48 \cdot 6}=0.29$ (emissivity 4 per cent.), and $\frac{16 \cdot 6}{41 \cdot 5}=0.40$

(emissivity 7 per cent.); mean $=0.35$.

For the helmet with the helmet-head space stuffed up, experiment 4 gives $\frac{10 \cdot 4}{62 \cdot 3}=0 \cdot 17$

The means give the following equations in the form of (7), (8) and (9):

$$
\left\{\begin{aligned}
R_{2}+C_{2}+V_{2} & =0.93 \\
.05 R_{2}+C_{2}+V_{2} & =0.35 \\
C_{2} & =0.17
\end{aligned}\right\} .
$$

These give the following values for the constituent conductances of the helmet-head space:

$\mathrm{C}_{2}=0.17 ; \mathrm{V}_{2}=0.15 ; \mathrm{R}_{2}=0.61 ; 0.07 R_{2}=0.04$ Similarly, for the space between helmet and dome, where one is fitted, we have the following results for the unventilated case :- 
TABLE 1

TESTS ON HELMETS IN STILL AIR

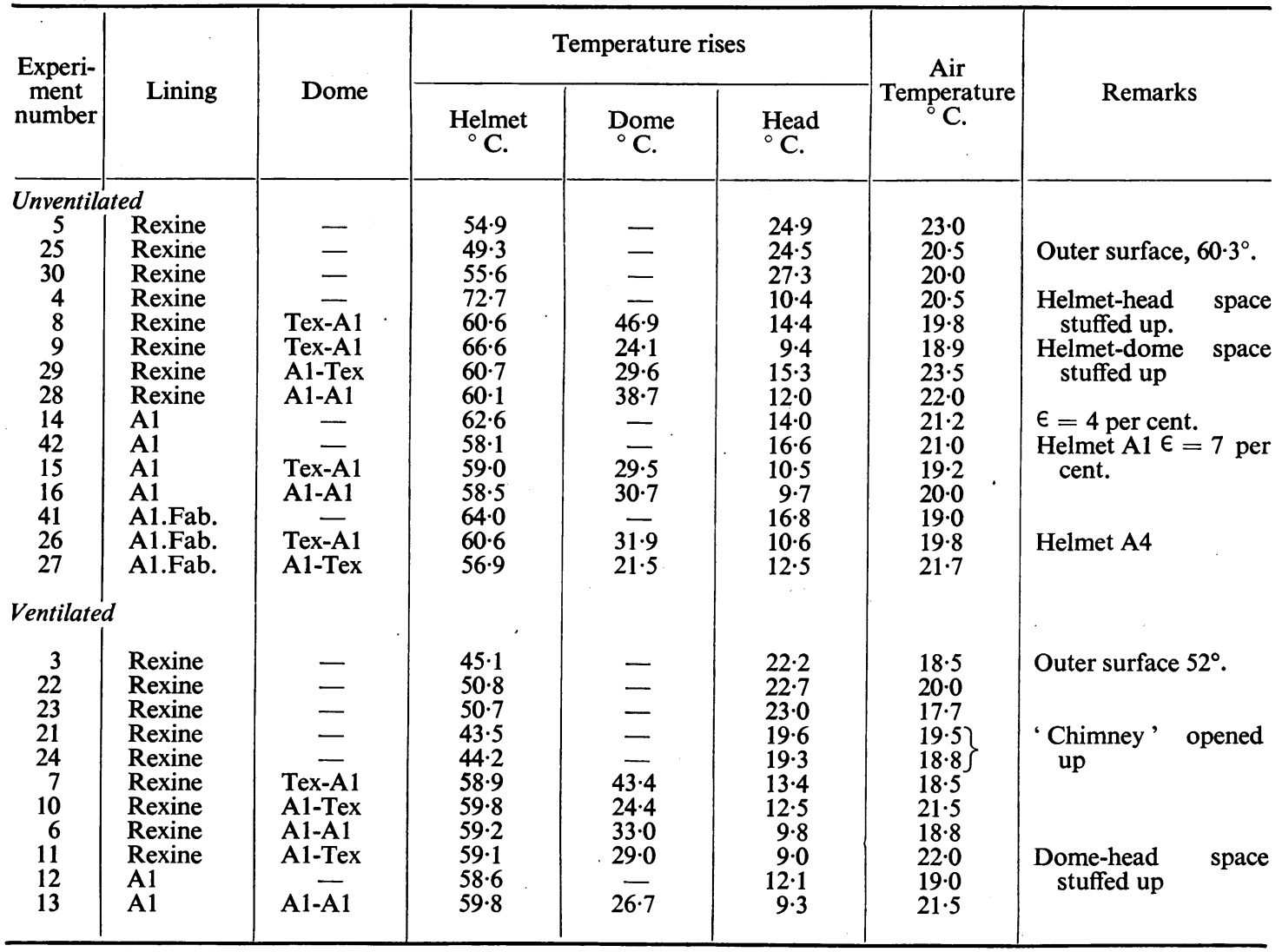

With both surfaces textile, experiment 8 gives conductance $=1.05$

With one surface aluminium foil and one textile, experiments 29 and 28 give conductances 0.49 and 0.56 ; mean value 0.53

With one surface textile and one aluminized fabric, experiments 15 and 26 give conductances 0.36 and 0.37 , mean value 0.36 .

With one surface aluminium foil and the other aluminized fabric, experiments 27 and 16 give values of 0.35 and 0.35 ; mean 0.35 .

With the space between helmet and dome stuffed up, experiment 9 gives conductance $=0 \cdot 22$.

Now we do not know the emissivities in this case, but if we assume that in the case where two aluminium faces were concerned the radiation transfer was negligible, we can calculate the emissivities for the cases where only one aluminium surface was concerned. Thus we get

$$
\left.\begin{array}{rl}
\mathrm{R}_{2}+C_{2}+V_{2} & =1.05 \\
\epsilon R_{2}+C_{2}+V_{2} & =.53 \text { (Al. lining, textile } \\
\epsilon_{B} R_{2}+C_{2}+V_{2} & =.36 \text { dome) } \\
C_{2}+V_{2} & =.35 \text { (Rexine lining, Al. } \\
C_{2} & =.22
\end{array}\right\}
$$

Here $\epsilon_{\mathrm{A}}$ and $\epsilon_{\mathrm{B}}$ are the emissivities of the aluminium foil and aluminized fabric respectively. These equations give for the constituent conductances of the helmet-dome space the following values:

$C_{2}=0.22 ; \quad V_{2}=0.13 ; \quad R_{2}=0.70 ; \quad \epsilon_{\mathrm{A}} R_{2}=0.18 ;$ $\epsilon_{\mathrm{B}} R_{2}=0.01$

from which we get values for the emissivities of the aluminium fỏil and aluminized fabric of 26 per cent. and 1 per cent. respectively. The former value is high, and it seems likely that the foil surface had become contaminated. Unfortunately, the foil lining was stripped and handled before this could be verified. The value of 1 per cent. for emissivity of the aluminized fabric comes from the small difference between two measured quantities, and should be taken as meaning merely that the emissivity was too small to be measured by this method.

For the space between dome and head, where the ventilation of the outer space would have little effect, we get the following conductances, obtained from both unventilated and ventilated experiments.

Inner surface of dome textile:-experiments 29 , 27 and 10 give values for the conductance of 1.07 , 1.39 and 1.05 ; mean 1.17 .

Inner surface of dome aluminized fabric; experiments $8,28,15,26,16,9,7,6$ and 13 give 0.44 , $0.45,0.55,0.50,0.46,0.64,0.45,0.42$, and 0.53 respectively; mean value 0.49 . 
Dome-head space stuffed up: experiment 11 gives $0 \cdot 45$. Thus we have

$$
\left.\begin{array}{rl}
R_{3}+C_{3}+V_{3} & =1.17 \\
\epsilon_{\mathrm{B}} R_{3}+C_{3}+V_{3} & =0.49 \\
C_{3} & =0.45
\end{array}\right\}
$$

If we take the value 6 per cent. for the emissivity of the aluminized fabric, we get the following values for the constituent conductances:

$C_{3}=0.45 ; V_{3}=0.02 ; R_{3}=0.70 ; 0.06 R_{3}=0.04$.

For the conductance of the material of the helmet itself we have the reading of the temperature of the outer surface in experiment 25 as evidence, for what it is worth. The difference in temperature between the inner and outer surfaces of the felt near the top of the crown was $11^{\circ} \mathrm{C}$., and this gives for the conductance of the solid part of the helmet, in the same units as before:

$$
C_{1}=2 \cdot 2
$$

It is difficult to be certain of the temperature of the outer surface when exposed to radiation, but this value for the conductance seems not unreasonable for a layer $0.3 \mathrm{~cm}$. thick of felt, being 13 times the purely conductive part of the conductance of the air in the helmet-head space, which is roughly 15 times as thick.

All these conductances are brought together in Table 2.

TABLE 2

\begin{tabular}{|c|c|c|c|c|}
\hline & $\begin{array}{l}\text { Material } \\
\text { of } \\
\text { helmet }\end{array}$ & $\begin{array}{c}\text { Helmet- } \\
\text { head } \\
\text { space. } \\
\text { No dome }\end{array}$ & $\begin{array}{l}\text { Helmet- } \\
\text { dome } \\
\text { space }\end{array}$ & $\begin{array}{l}\text { Dome- } \\
\text { head } \\
\text { space }\end{array}$ \\
\hline $\begin{array}{l}\text { Conduction (C) } \\
\text { Convection (V) } \\
\text { Radiation (R) (no } \\
\text { Al face) }\end{array}$ & $\begin{array}{l}2.2 \\
0.0 \\
0.0\end{array}$ & $\begin{array}{l}0 \cdot 17 \\
0 \cdot 15 \\
0 \cdot 61\end{array}$ & $\begin{array}{l}0 \cdot 22 \\
0.13 \\
0.70\end{array}$ & $\begin{array}{l}0.45 \\
0.02 \\
0.70\end{array}$ \\
\hline $\begin{array}{l}\text { Radiation }(\epsilon \mathrm{R}) * \\
\text { (one A1 face) }\end{array}$ & 0.0 & 0.04 & 0.04 & 0.04 \\
\hline
\end{tabular}

CONSTITUENT CONDUCTANCES OF UNVENTILATED HELMET SPACES : ARBITRARY UNITS

* An emissivity of 6 per cent. is here assumed, i.e. that of the aluminized fabric when new.

It is as well here to repeat the caution that these figures should be regarded as giving the orders of magnitude only. None the less, they do not seem unreasonable when compared amongst themselves. The conduction progressively increases as we consider narrower and narrower spaces, whilst the convection decreases, as it should. The radiation remains of the same order, which is again what we should expect, since it will depend upon the degree to which the outer surface of the space considered surrounds the inner, and this does not alter much. We can apply a quantitative check to the conduction figures, for the helmet-dome space and the domehead space in series should have the same conductive conductance as the helmet-head space, since the dome occupies a negligible volume. Adding, therefore, the reciprocals of the conduction figures for the two former spaces, and taking the reciprocal of the sum, we get $0 \cdot 15$, which may be compared with the experimental value of 0.17 for the helmethead space.

\section{Effect of Ventilation}

So far we have only been considering those cases in which ventilation by air from outside was prevented by stopping up the 'chimney' and the gap between the head band and the helmet. All the heat exchanges involved were between helmet and head, or between helmet and dome, and dome and head. We have now to find what is the extra effect of allowing ventilation to take place.

In Table 3 are collected data from Table 1 arranged to show the effects of ventilation. Each line is concerned with one arrangement of the helmet as described in the first and second column; and the third and fourth columns show the mean rises of temperature for the corresponding unventilated and ventilated cases, respectively. The fifth column gives the differences, and it will be seen, as might be expected, that ventilation lowers the head temperature in every case. Of particular interest are the third and fourth rows, which show the results of experiments in which the little detachable cover which fits over the top ventilator had been raised so as to increase the size of the apertures. It will be seen that this has produced a marked increase in the cooling due to ventilation, a fact which suggests that a noticeable improvement in performance could be brought about by a small change in design here. The ventilator cover is detachable, so that no alteration to the helmet itself would necessarily be involved, and indeed, new covers could be fitted into existing helmets without any trouble. This is discussed later.

The ventilation may produce its effects in three ways: firstly, by direct cooling of the head or dome; secondly, by cooling the helmet and so reducing the flow of heat from it to the head; and thirdly, by giving increased opportunities for turbulence of the air inside the helmet, so increasing the flow of heat to the head. In columns 6-8 of Table 3 are shown the rises in temperature of the inner surface of the crown of the helmet in the unventilated and ventilated conditions, and the difference which shows the effect of ventilation. Column 9 is calculated from 3,6 , and 8 , and shows what would be the effect on the head temperature of the decrease in helmet temperature shown in column 8 if it were acting alone, worked out on the assumption that the head temperature rise is proportional to the helmet temperature rise. Column 10, obtained by subtracting column 9 from column 5, shows that part of the effect of ventilation on head temperature which is due to direct cooling or to increase in turbulence. The figures are somewhat variable owing to their being deduced from small differences between large quantities, but one can draw the conclusion that the effects on both helmet and head are important, especially for the domeless helmet. 
TABLE 3

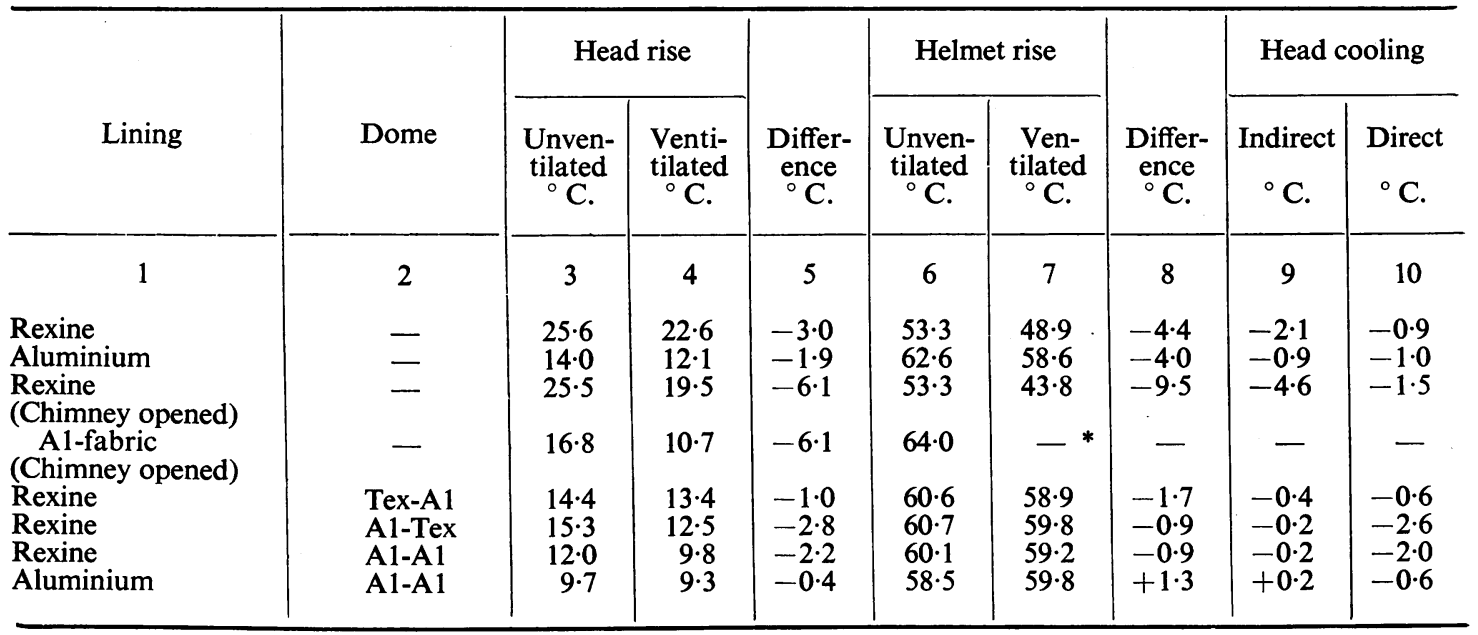

* An accident happened in this experiment, the helmet thermocouple coming adrift half-way through.

The conditions under which these experiments were done were rather artificial as regards ventilation, since the helmet was enclosed in a vertical tunnel of black cloth above the top of which was the source of heat. The cloth reached to the floor, however, and it was not possible to detect an appreciable updraught in the tunnel.

\section{Determination of External Heat Exchanges}

The external heat loss is more difficult to measure than the internal heat transfer, and in fact, it has only been possible to set a minimum to it. This, however, proved sufficient since it was found that the heat lost by the outer surface of the helmet is, as one would expect, much greater than that lost by the inner surface, and this is all that we require to know at the present. If the internal heat loss by the helmet was comparable to the external loss, an improvement in the internal insulation would result in a rise in temperature of the helmet. This would partially nullify the good effect of the increased insulation. As it is, however, the helmet temperature will not vary greatly as the internal insulation is improved.

The same helmet as used for most of the previous experiments was set up with Rexine lining and no dome, and with the ventilator and space round the head band stopped up (i.e. in the "unventilated' state). Thermocouples were attached to the head and to the inner and outer surfaces of the top of the crown. The helmet was then exposed to radiation for 6 hours. The crown temperatures rose quickly during the first hour and at a much slower rate during the next 3 hours. During the last 2 hours there was no perceptible rise. The head temperature, on the other hand, was steadily rising the whole time, though at a diminishing rate. Thus the difference in temperature between the helmet and the head was steadily decreasing during the latter half of the run and, therefore, also the heat transfer from helmet to head. Since the heat supplied to the helmet by the radiation was constant, the diminishing loss of heat inside would produce a rise in temperature of the helmet until the increased loss outside compensated for it, and the extent of the temperature rise would depend upon the ratio of the internal and external losses. Assuming both to be proportional to the temperature differences producing them, and that $T_{\mathrm{O}}$ and $T_{\mathrm{H}}$ are the only variables, we get by differentiating (2):-

$$
\begin{array}{lll} 
& 0=K \frac{d T_{\mathrm{O}}}{d t}-C \frac{d T_{\mathrm{H}}}{d t} \quad . . & . \\
\text { or } & \frac{K}{C}=\frac{d T_{\mathrm{H}}}{d t} / \frac{d T_{\mathrm{O}}}{d t} \\
\text { or since } & K=C+C_{\mathrm{E}} \\
& & \frac{C_{\mathrm{E}}}{C}=\left\{\frac{d T_{\mathrm{H}}}{d t} / \frac{d T_{\mathrm{O}}}{d t}\right\}-1 . .
\end{array}
$$

If at the time considered the helmet has not reached ' equilibrium ' with the surroundings, there will be an additional rise in temperature due to this fact, so that (14) sets a minimum value for $C_{\mathrm{E}} / C$. (In other words, we have neglected the thermal capacity of the helmet in (13) and (14).)

The results of the experiment are shown in fig. 3 . It is impossible to say exactly what $d T_{\mathrm{o}} / d t$ was at the end of the experiment, but if we take the increases in temperature between 150 and 350 minutes exposure as being proportional to the temperature rates of change we find that $C_{\mathrm{E}} / C \nless 5$. In doing this we have almost certainly underestimated the ratio. Moreover, the helmets used had a Rexine lining; an aluminium-lined helmet would show a still larger ratio. Thus we can be sure that the external heat loss is always large compared with the internal transfer of heat from helmet to head. This is all that we need to know at present, since it means that nearly the full benefit will be derived from any improvement in the internal insulation of the helmet. In the laboratory, the helmet is surrounded by air 


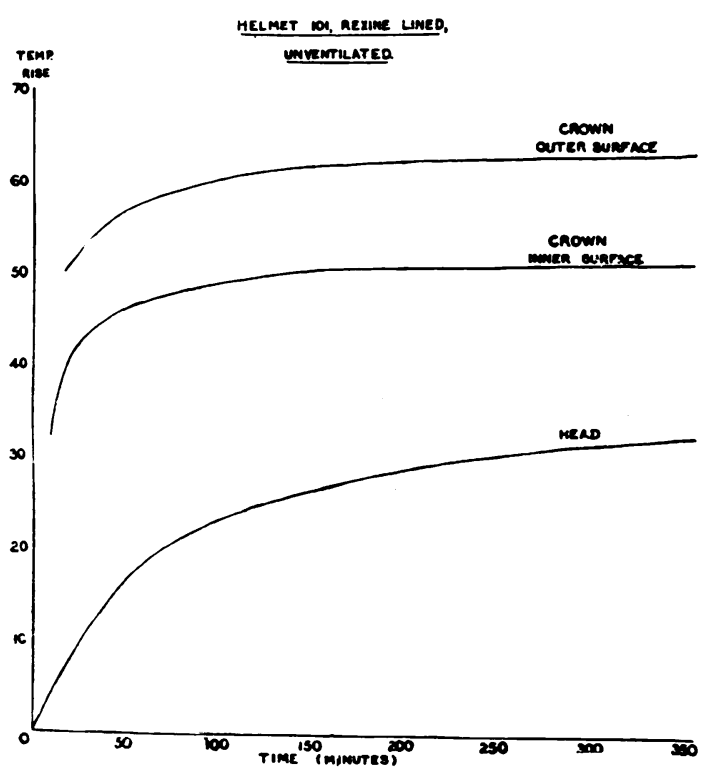

Fig. 3.-Temperature rise-time curves in ${ }^{\circ} \mathrm{C}$ for helmet and plaster of Paris head.

much cooler than itself so that this large heat loss is an artificial condition. In tropical use, the surroundings will be very similar in temperature to the helmet but the relatively large conductance between them still means that the helmet temperature is little affected by changes in the internal conductance.

\section{Absorption of Sunlight by Helmet Coverings}

As we have seen, the ideal covering for a military helmet from a thermal point of view would be one which had the lightest permissible khaki colour, combined with the least possible absorption in the near infra-red. Experiments with the electric radiator cannot give us any idea as to the relative merits of helmet coverings, since the radiation produced is very far from being similar to sunlight. Consequently, use was made of the high-intensity carbon arc, the light from which has a spectral distribution approaching closely that of sunlight (Rees and Ogden, 1944 and 1946). Fabrics to be compared were formed into sleeves which fitted tightly over a set of similar glass tubes about 1 inch in diameter and 4 inches long. These tubes, which acted as calorimeters, were filled with water, and the bulb of a thermometer was fixed centrally in each. Several such samples wrapped round their calorimeters were placed side by side in the light from the arc, and their rates of rise of temperature were noted. Since the beam from the arc is not uniform, the samples and calorimeters were changed round so that each occupied a given position in turn and the means of the temperature rises were taken. To protect the samples from draughts they were exposed in a lidless cardboard box. The method cannot be described as accurate but it is simple and rapid, and probably good enough for the present purpose. Some results are given below for a set of fabrics as far as possible of similar thickness and structure.

Between the two extremes of aluminium foil (most efficient covering) and black cloth (least efficient) neither of which is practical for military helmets, white cloth provides the best covering from the point of view of heat insulation.

Members of H.M. Navy are thus better protected than members of the land forces, for though white coverings can be used by the Navy, they are not permitted by the land forces on account of their conspicuousness. As the results show, there is little room for improvement, however, in the coverings of the standard military type.

TABLE 4

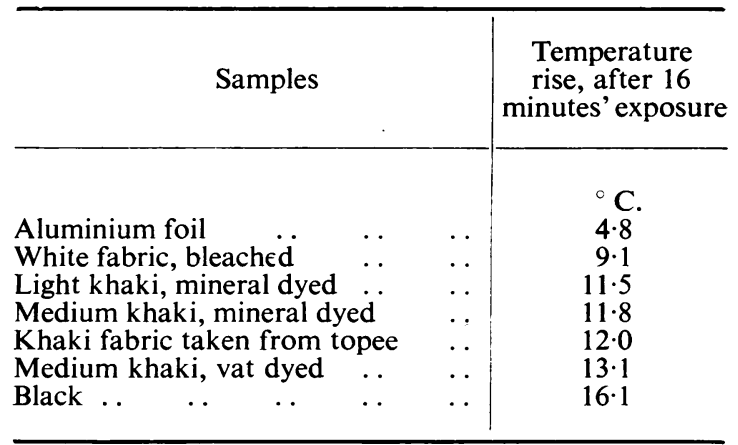

\section{Discussion : Possibility of Improving Helmets}

Before possible improvements are considered, it will be of interest to show figures for various designs of helmet that have been used in the past and have led up to the present design. In Table 5 are given the rises in temperature at the crown of the plaster of Paris head for various types of tropical helmet. The lower this rise the more efficient is the helmet. The weights of the samples are also given. In all cases the helmets are in the 'ventilated' condition, i.e. there is no interference with the system of ventilation provided by the helmet. It will be seen that the earlier helmets were lighter than the present army pattern topees, but were not so good as regards protection from the heat. This difference is mainly due to the aluminium lining used at the present time. (The first five in the above table had no metal linings.) The older helmets were also less well-ventilated than the present model, having narrower gaps between head band and crown.

In Table 6, we give similar results on British and American steel helmets both in still air and in a horizontal wind speed 2.5 miles per hour. These results are included for interest, and have no connexion with the investigation described in this report.

Now let us consider all the heat exchanges in turn with a view to deciding whether any improvement on the present helmets can be brought about. We will take them in the order in which they occur when sunlight falls on the helmet. 
TABLE 5

TESTS ON HELMETS IN STILL AIR

\begin{tabular}{|c|c|c|}
\hline Sample & $\begin{array}{l}\text { Weight, } \\
\text { oz. }\end{array}$ & $\begin{array}{c}\text { Temperature } \\
\text { rise after } \\
2 \text { hours } \\
{ }^{\circ} \mathrm{C} .\end{array}$ \\
\hline $\begin{array}{cc}\text { 'Lord Roberts' } & \text { model } \\
\text { (Papier maché?) } & \cdots \\
\text { Ladysmith model } & \text { (Papier }\end{array}$ & $7 \cdot 0$ & $28 \cdot 1$ \\
\hline $\begin{array}{ccc}\text { Ladysmith } & \text { model (Papier } \\
\text { maché?) } & \ldots\end{array}$ & $7 \cdot 6$ & $25 \cdot 0$ \\
\hline $\begin{array}{l}\text { Cork helmet } \\
\text { Pith helmet }\end{array}$ & $11 \cdot 3$ & $20 \cdot 3$ \\
\hline $\begin{array}{l}\text { Pith helmet } \\
\text { Modern felt helmet, no Ai }\end{array}$ & 8.0 & 18.0 \\
\hline $\begin{array}{l}\text { Modern felt helmet, no A1 } \\
\text { lining } \ldots\end{array}$ & 14.7 & 2 \\
\hline 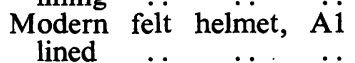 & & $22 \cdot 2$ \\
\hline lined Modern cork helmet, $\ddot{\mathrm{A}} \dot{1}$ & $14 \cdot 7$ & $11 \cdot 5$ \\
\hline $\begin{array}{c}\text { lined } \text { Modern felt helmet, } \ddot{\mathrm{A}} 1\end{array}$ & $15 \cdot 0$ & $10 \cdot 9$ \\
\hline $\begin{array}{l}\text { lined, and with } \mathrm{A} 1 \text { drop } \\
\text { lining mounted by manu- }\end{array}$ & & \\
\hline $\begin{array}{l}\text { facturer } \\
\text { Modern felt helmet, } \ddot{\mathrm{A}} 1 \\
\text { lined, but with drop } \\
\text { lining mounted to avoid }\end{array}$ & $15 \cdot 5$ & $11 \cdot 1$ \\
\hline $\begin{array}{l}\text { contact } \\
\text { Modern felt helmet, no } \ddot{\mathrm{A}} \mathrm{i}\end{array}$ & $15 \cdot 5$ & $9 \cdot 3$ \\
\hline $\begin{array}{l}\text { lining, but with A1 drop } \\
\text { lining, no contact }\end{array}$ & $15 \cdot 5$ & $9 \cdot 8$ \\
\hline
\end{tabular}

TABLE 6

\begin{tabular}{|c|c|c|c|}
\hline \multirow{2}{*}{ Helmet } & \multirow{2}{*}{$\begin{array}{l}\text { Weight, } \\
\text { oz. }\end{array}$} & \multicolumn{2}{|c|}{$\begin{array}{l}\text { Temperature rise } \\
\text { after } 2 \text { hours }\end{array}$} \\
\hline & & $\begin{array}{l}\text { In.still } \\
\text { air }\end{array}$ & $\begin{array}{l}\text { In wind } \\
\text { speed of } \\
2.5 \text { miles } \\
\text { per hour }\end{array}$ \\
\hline & & ${ }^{\circ} \mathrm{C}$. & ${ }^{\circ} \mathrm{C}$. \\
\hline $\begin{array}{l}\text { British steel helmet } \\
\text { British steel helmet plus }\end{array}$ & 40 & $27 \cdot 5$ & $5 \cdot 1$ \\
\hline $\begin{array}{l}\text { Isoflex cover }{ }^{*} \\
\text { American steel helmet with }\end{array}$ & 45 & $12 \cdot 9$ & $2 \cdot 2$ \\
\hline $\begin{array}{l}\text { composite lining } \\
\text { Lining of American steel }\end{array}$ & 45 & $24 \cdot 9$ & $6 \cdot 2$ \\
\hline $\begin{array}{l}\text { helmet } \ddot{\text {. }} \\
\text { Wool-felt solar topee, no }\end{array}$ & 9 & 30.9 & $7 \cdot 6$ \\
\hline $\begin{array}{c}\text { A1 lining } \\
\text { Wool-felt solar topee with }\end{array}$ & 15 & $22 \cdot 2$ & $3 \cdot 8$ \\
\hline $\begin{array}{l}\text { A1 lining } \\
\text { Wool-felt solar topee, no } \\
\text { A1 lining but with chim- }\end{array}$ & 15 & $11 \cdot 5$ & $1 \cdot 6$ \\
\hline $\begin{array}{l}\text { ney blocked up .. } \\
\text { Bare head }\end{array}$ & 15 & $26 \cdot 5$ & $\begin{array}{r}5 \cdot 3 \\
27 \cdot 0\end{array}$ \\
\hline Bare head $\quad \ldots$ & & $47 \cdot 0$ & $27 \cdot 0$ \\
\hline
\end{tabular}

* 'Isofiex' is made of corrugated sheets of cellulose acetate stuck together layer upon layer, thus forming a "honeycomb" structure. The cover referred to consists of a shell of Isoflex, roughly is ench thick, shaped to fit the outside of the steel
is enclosed two layers of khaki drill.

\section{(a) Absorption of the Sunlight .}

We have seen that a considerable diminution in the amount absorbed could be brought about by the use of a metallic or white covering, but that for military purposes, where a coloured covering is essential, there is not much room for improvement.

\section{(b) Radiation from the Outer Surface}

If this could be increased, the helmet would be cooler. For low-temperature radiation, however, most, if not all, textiles are nearly perfect radiators, so that the existing covering is already the best that can be attained in this respect.

(c) Conduction and Convection from the Outer Surface

An increase in this would be of advantage, and could be achieved by enlarging the surface area. This is done in the case of air-cooled engines by adding fins, but it is doubtful whether much could be done with a helmet without unduly complicating the construction or adding to the weight.

\section{(d) Conduction through the Helmet}

This can be, and is, cut down by increasing the thickness of the helmet, whilst keeping its conductivity low, as in the case of the pith helmet. The stiffened wool felt used in the present army sun helmets is very inefficient in its insulation for a given weight, pith being about 20 times better in this respect. The difficulty here is solely that of manufacturing under war-time conditions a helmet which is thicker without being heavier. There are a number of light 'expanded' materials available which would be suitable, but many of them are in short supply, and most would probably require more labour in the manufacture of the helmets. The shellacked felt at present employed lends itself to rapid production of the body of the helmet by a hot-pressing process. The weight of the present helmet is largely due to the desire for stiffness combined with robustness. If the former were sacrificed there would be less need for the latter, and a much lighter but equally effective helmet could be designed. It should be borne in mind, however, that stiffness in certain parts is essential in order to preserve adequate ventilation by keeping the helmet away from the head. Soft hats with the head band attached directly to the hat are poorly ventilated even if they have a few small holes punched in them. This question of ventilation is discussed later.

If it were worth while, an outer covering of Isoflex, like that designed at the Shirley Institute for steel helmets, would no doubt prove effective as an addition to the standard felt helmets, though it would add to their weight.

\section{(e) Radiation Inwards from Helmet}

This is, as we have seen, the most important means of transfer of heat in a helmet not lined with metal, but is cut down by the use of clean aluminium foil to an amount small compared with the irreducible conduction. We have not been able to test a helmet lined with aluminium which has been in use, so 
that we cannot tell how far the lining retains its effectiveness under practical conditions. The use of a drop lining might help to keep the true lining clean, but this advantage is probably outweighed by the hindrance to ventilation of the head, apart from other disadvantages such as the use of valuable aluminium. An aluminium-lined topee with a double-sided aluminium drop lining is admittedly the most efficient existing system for reducing the amount of heat that reaches the head. This, however, is only part of the story. With such a topee there is almost complete lack of ventilation of the head, which, under tropical conditions, is surely a factor of the highest importance. Perspiration must be got rid of for comfort, and in a drop-lined topee there is little means of doing this, with the result that the helmet soon becomes uncomfortable to wear and may be discarded.

If we eliminate the drop lining, the helmet becomes slightly less efficient as an insulator, but is still much superior to one without the metal lining. In this connexion it should be pointed out that the high insulating efficiency of a topee fitted with a drop lining is only attained if the latter is so mounted that no contact occurs anywhere, either with the head or with the helmet itself. Those who have handled drop linings will realize how difficult it is to produce and maintain this condition. The difference in efficiency is shown in the last three lines in Table 5.

\section{(f) Conduction from Helmet to Head}

There is no practically useful substance with a thermal conductivity less than that of air. Hence the conduction of heat from helmet to head cannot be reduced below its present level.

\section{(g) Convection of Heat from Helmet to Head}

This can be stopped by filling up the space inside the helmet with a porous material, which would at the same time stop radiation without the use of metal, and whether the material was clean or not. At the same time, however, it would prevent ventilation, and there would be little, if any, gain over the present aluminium-lined helmet. Moreover, the porous material might afford convenient lodging for insects.

\section{(h) Ventilation}

This reduces the effective heat flow to the head by cooling the helmet, by direct cooling of the head, and by allowing evaporation of moisture from the head, thus also contributing to the general comfort. This is the direction in which, as it seems to us, most improvement could be brought about in the standard helmet without radical alteration in manufacture. The present helmet has taken a long step forward by introducing the wide gap between the head band and helmet body but the ventilator at the top (the 'chimney') seems to have been designed on the old principle that any hole is big enough for air.* We have already given in Table 3 some figures showing the effect of raising the ventilator cover of a standard helmet not provided with an aluminium lining. In Table 7 are shown the results of some experiments with a helmet which had such a lining. They were obtained, like the rest, on the dry plaster of Paris ' head,' and it must be remembered that, with an actual moist head, any increase in ventilation would probably show a larger effect. In the first experiment the chimney was blocked up to provide a 'zero.' (The space round the head band was left free throughout.) In the second experiment the chimney was in its normal state, and in the third the brass retaining strips were rotated about the rivet holding them so that they did not obscure the apertures. In the fourth experiment a new pattern of chimney was substituted for the usual one without any alteration to the helmet itself.

TABLE 7

\begin{tabular}{|c|c|c|}
\hline State of ventilator & $\begin{array}{l}\text { Tempera- } \\
\text { ture rise } \\
\text { of head }\end{array}$ & $\begin{array}{l}\text { Effect of } \\
\text { ventilator }\end{array}$ \\
\hline & ${ }^{\circ} \mathrm{C}$. & ${ }^{\circ} \mathrm{C}$. \\
\hline $\begin{array}{lll}\text { Chimney stopped up } & \ldots & \ldots \\
\text { Normal state } & \ldots & \ldots\end{array}$ & $\begin{array}{l}15 \cdot 0 \\
13 \cdot 9\end{array}$ & $\overline{1 \cdot 1}$ \\
\hline $\begin{array}{l}\text { Brass strips rotated to a new } \\
\text { position } \\
\text { New pattern of chimney }\end{array}$ & $\begin{array}{l}13 \cdot 8 \\
12 \cdot 4\end{array}$ & $\begin{array}{l}1 \cdot 2 \\
2 \cdot 6\end{array}$ \\
\hline
\end{tabular}

The rotation of the brass strips was tried because it was conjectured that their position opposite to the apertures would result in an appreciable obstruction. However, this appears not to be so. It will be seen that the new pattern of chimney is more than twice as effective as the normal pattern. The former was constructed from a sheet of metal bent into the arc of a cylinder, so as to leave considerable apertures at the two sides. The present and the new pattern of chimney are shown diagrammatically in fig. 4 .

To sum up, the only improvements which could be made as regards thermal insulation without radical changes in design are the substitution of thicker material and a larger ventilator cover. The former is probably impracticable as a war-time measure, and thus we are left with the ventilator as the only possibility of improvement.

If we wanted to make the best possible helmet out of the material that has passed through our hands, and irrespective of the question of quantity production, we should take the pith helmet, line it with aluminium foil, and fit it with a much larger ventilator (it has smaller apertures even than the Army pattern felt helmet). The result would be a

\footnotetext{
* The unsoundness of this principle can be seen in a general way by the following argument. With a given pressure distribution tending to produce motion of the air, the rate of flow will be inversely proportional to the resistance (i.e. dissipation of energy) brought about by surrounding matter. In the helmet this resistance will partly occur in the space between helmet and head, and partly at the chimney, and whatever the type of flow the resistance at the chimney is likely to be the greater as long as the chimney apertures are very small compared with the dimensions of the space inside the helmet.
} 

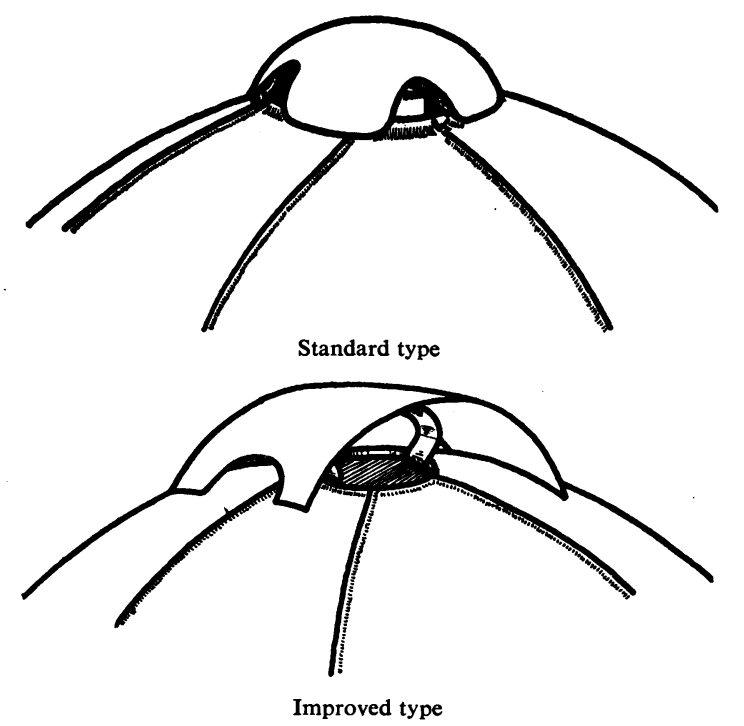

FIG. 4.-Diagrams of helmet ventilators.

great improvement on any helmet we have seen so far as good insulation with light weight goes.

\section{Appendix. Emissivity of Lining Materials}

In order that a lined topee shall be a good insulator, its lining must have a low emissivity, that is, it must be a poor emitter of radiant heat. The emissivity of a surface is defined as the ratio of the intensity of the radiation it emits at a given temperature to the corresponding intensity of the radiation from a perfectly black body at the same temperature. It is usually expressed as a percentage, so that if a surface has an emissivity of 100 per cent. it emits the same amount of energy as a black body under the same conditions, which is the maximum possible under those conditions.

Bright metallic surfaces have very low emissivities and, therefore, make very suitable linings for sun helmets. The ability of aluminium to retain its brightness makes it the obvious choice; indeed, the only reasonable alternative would be tin, which was probably scarcer than aluminium during the war. If foils of the same thickness were used, tin would cost about six times as much as aluminium at war-time prices.

The majority of non-metallic surfaces (including paints and textiles), no matter how white or glossy, have high emissivities, and are, therefore, unsuitable as linings. Even aluminium paint will not do, owing to the organic vehicle which covers the metal particles. Contamination of a bright metal surface by oil, grease, etc., produces a marked increase in the emissivity of the surface, as does a film of oxide in some cases (e.g., copper). The oxide film which always exists on the surface of bright aluminium does not seem to interfere appreciably.

In Table 8 are given the emissivities at $100^{\circ} \mathrm{C}$. of various types of surface, measured in this laboratory by means of a Leslie cube and thermopile. In the third column are given, where possible, the temperature rises of the dummy head when covered by helmets lined with the surface in question. The fourth column is explained later.

It will be seen from these results how essential it is for the lining to be a bright, uncontaminated one. Sprayed metallic linings were found to be quite impractical, as they were very readily contaminated.

In the fourth column in Table 8 are added, as a matter of interest, temperature rises for the plaster of Paris head calculated from the emissivities given

TABLE 8

\begin{tabular}{|c|c|c|c|}
\hline \multirow[b]{2}{*}{ Sample } & \multirow[b]{2}{*}{$\begin{array}{l}\text { Emissi- } \\
\text { vity at } \\
100^{\circ} \mathrm{C} . \\
\text { per cent. }\end{array}$} & \multicolumn{2}{|c|}{ Temperature rise } \\
\hline & & $\begin{array}{c}\text { Experi- } \\
\text { mental } \\
{ }^{\circ} \mathrm{C} .\end{array}$ & $\begin{array}{l}\text { Calcu- } \\
\text { lated } \\
{ }^{\circ} \mathrm{C} .\end{array}$ \\
\hline $\begin{array}{l}\text { Bright aluminium foil } \\
\text { Bright aluminium foil with }\end{array}$ & 4 & $11 \cdot 5$ & $(11 \cdot 5)$ \\
\hline a light smear of oil & 26 & - & $14 \cdot 7$ \\
\hline Bright aluminium paint.. & 65 & $19 \cdot 1$ & $19 \cdot 8$ \\
\hline $\begin{array}{l}\text { Dull aluminium paint } \\
\text { 'Sprayed }\end{array}$ & 74 & $20 \cdot 6$ & $20 \cdot 8$ \\
\hline face $\quad \ldots \quad \ldots \quad \ldots$ & 25 & $15 \cdot 7$ & $14 \cdot 7$ \\
\hline $\begin{array}{l}\text { Aluminized fabric } \\
\text { Aluminized fabric with }\end{array}$ & $5 *$ & $11 \cdot 8 *$ & $11 \cdot 5$ \\
\hline $\begin{array}{cc}\text { 'cellophane' face } & \ldots \\
\text { ' Rexine' cloth } \quad . . & \ldots\end{array}$ & $\begin{array}{c}84 \\
90-100\end{array}$ & $\begin{array}{l}20 \cdot 9 \\
22 \cdot 2\end{array}$ & $\begin{array}{r}21 \cdot 9 \\
23-24\end{array}$ \\
\hline
\end{tabular}

* The temperature rise with this helmet after it had been in store for some time rose to $13^{\circ} \mathrm{C}$. presumably owing to a change in emissivity of the lining. The emissivity corresponding to this application of very thin foil, not by spraying or painting.

in the second column, using also the conductance data given in Table 2 and the method of combining them described in Section 3. These data leave an indeterminate constant depending upon the intensity of the radiation falling on the helmet in these experiments. This was adjusted to make the calculated value agree with the experimental $\left(11 \cdot 5^{\circ} \mathrm{C}\right.$.) in the case where the bright aluminium foil was used. Since the experimental values were found with the helmet ventilated, and the conductance calculations give values for the unventilated helmet, small corrections were applied to allow for the difference in the effect of ventilation when the head temperature rise differs from $11 \cdot 5^{\circ} \mathrm{C}$. The first two lines in Table 3 show a difference of $1 \cdot 1^{\circ} \mathrm{C}$. in the ventilation effect when the head temperature rise (unventilated) changes from $14 \cdot 0^{\circ} \mathrm{C}$. to $25 \cdot 6^{\circ} \mathrm{C}$. The corrections applied in calculating column 4 of Table 8 were assumed proportional to the difference of the head temperature rise from $11 \cdot 5^{\circ} \mathrm{C}$. They did not exceed $1 \cdot 1^{\circ} \mathrm{C}$. in any case. The agreement throughout is quite satisfactory.

\section{Acknowledgement}

The authors wish to thank Mr. L. W. Ogden for his assistance with the experimental work.

\section{REFERENCES}

Rees, W. H., and Ogden, L. W. (1944). Shirley Inst. Mem., 19, 59. (1946). J. Textile Inst., 37, 113.

Roberts, J. K. (1933). Heat and Thermodynamics. 2nd Ed., London,

Blackie.
Rubens, H., and Hagen, E. (1903). Ann. Physik., 11, 873. (See also Wood, R.W. (1934). Physical Optics. 3rd Ed., Ch. 16 New York, Macmillan.) 